\title{
MULHERES E ÁLCOOL: UMA QUESTÃO DE GÊNERO ${ }^{1}$
}

\author{
WOMEN AND ALCOHOL: A MATTER OF GENDER
}

Dária Sirqueira Matsumoto ${ }^{2}$

\section{RESUMO}

Este artigo tem como objetivo refletir sobre a importância da utilização da categoria analítica de gênero no atendimento de mulheres que adoeceram pelo uso de álcool. Os resultados de algumas dessas reflexões são apresentados neste ensaio teórico que teve como principal eixo a utilização da tríade gênero, integralidade e Questão Social. Sob esse aspecto, essas "lentes" de leitura da realidade social, expressas no atendimento, podem propiciar ao assistente social novas possibilidades de intervenção profissional.

PALAVRAS-CHAVE: Álcool. Mulheres. Gênero. Questão Social.

\begin{abstract}
The aim of this study was to reflect upon the importance of using the analytical category of gender in the care of women who became ill due to alcohol abuse. The results of some of these reflections are presented in this theoretical essay, whose main axis was the use of the triad gender, comprehensiveness and social question. From this aspect, these reading "lenses" of the social reality, expressed in the care, may provide the social worker with new possibilities of professional intervention.
\end{abstract}

KEYWORDS: Alcohol. Women. Gender. Social Question.

\section{APRESENTAÇÃO}

O álcool é uma das substâncias psicoativas que tem o seu consumo liberado e incentivado na sociedade moderna. De acordo com a Organização Mundial da Saúde

\footnotetext{
${ }^{1}$ Este artigo foi desenvolvido no contexto de pós-graduação, como parte dos requisitos para a obtenção do título de especialista em Serviço Social em Saúde Coletiva, sob a orientação das Profas. Doutoras, Damares Pereira Vicente e Maria Lúcia Garcia Mira.

${ }^{2}$ Assistente Social, especialista em Serviço Social na Saúde Pública (IIER/SES-SP), especialista em Saúde Coletiva (FMU-SP), mestranda em Serviço Social (PUC/SP). E-mail: daria.sirqueira@gmail.com. Telefone: 5511 96199-1105.
}

Serv. Soc. \& Saúde, Campinas, SP v. 12, n. 2 (16), p. 237-258, jul./dez. 2013 ISSN 1676-6806 
(OMS), o uso de álcool é um dos três principais fatores de risco para a carga global de doenças. Pereira Dantas (2012) refere que, nos países em desenvolvimento, como é o caso do Brasil, a ingestão de bebidas alcoólicas é a principal causa de morte e representa entre $8 \%$ e $14,9 \%$ do total de doenças da população.

A autora ainda destaca que o uso abusivo de álcool é responsável por 3\% de todas as mortes que ocorrem no mundo. Essas mortes estão relacionadas a quedas, câncer, violência doméstica, doenças sexualmente transmissíveis, desentendimentos familiares e amorosos, intoxicações, cirrose hepática, homicídios e acidentes de trânsito.

No que diz respeito à violência e suas diferentes manifestações, o uso abusivo de álcool pode ser considerado um dos principais "combustíveis" para o aumento dos índices da violência urbana.

O Centro de Informações sobre Saúde e Álcool (CISA) aponta que estudos epidemiológicos indicam o surgimento de novas tendências no consumo de álcool, com o aumento em países da América Latina (AL) e nos Estados Unidos da América (EUA). No caso do Brasil, nos últimos anos, houve o aumento da visibilidade de casos relacionados ao álcool e direção veicular. Essa maior visibilidade está associada ao crescimento de acidentes e mortes no trânsito, associado à implementação de dispositivos legais ${ }^{3}$ que visam inibir a embriaguez ao volante.

O consumo de bebidas alcoólicas é um comportamento comumente encontrado em diferentes culturas. Em nossa sociedade, é habitual o uso de álcool em cerimônias religiosas, eventos sociais e culturais, situações de negócios, dentre outros momentos da vida cotidiana. Isso contribui para a naturalização da substância na vida dos indivíduos, assim como para "maquiar" possíveis danos gerados nos aspectos sociais, psíquicos e físicos dos usuários.

Sobre os padrões de consumo da população brasileira, o II Levantamento Nacional de Álcool e Drogas (LENAD-2012) aponta que, em relação ao I Levantamento, realizado em 2006, não houve aumento significativo ${ }^{4}$ nas taxas de abstinência. No entanto, registra-se aumento de $20 \%$, na proporção de bebedores frequentes $^{5}$, para $54 \%$, em 2012, em relação a 2006, que era de $45 \%$.

\footnotetext{
${ }^{3}$ A Lei n. 12. 760/2012, também conhecida como Lei Seca, altera o artigo 306 do Código Brasileiro de Trânsito que tipifica o crime de embriaguez ao volante.

4 48\%, em 2006, para 52\%, em 2012.

${ }^{5}$ Indivíduos que bebem uma vez por semana ou mais.
}

Serv. Soc. \& Saúde, Campinas, SP v. 12, n. 2 (16), p. 237-258, jul./dez. 2013 ISSN 1676-6806 
A pesquisa destaca a ampliação significativa entre as mulheres, pois os casos saltaram de 29\%, em 2006, para 39\%, em 2012.

O uso de volume excessivo de álcool, em curto espaço de tempo, é prática conhecida, na literatura internacional, como "beber em binge" mundialmente para definir o "uso pesado episódico do álcool". De acordo com o I Levantamento Nacional sobre os Padrões de Consumo de Álcool na População Brasileira (2007), esse tipo de consumo é mais perigoso, já que frequentemente associase a problemas físicos, sociais e mentais, ao comprometer a capacidade cognitiva, coordenação motora, piorar a capacidade de julgamento, etc.

Em relação a essa forma de consumo, o LENAD-2012 aponta o aumento da prática do beber em binge, de 45\%, em 2006, para 59\%, em 2012, entre a população de bebedores. Novamente, observa-se crescimento na população feminina, de $36 \%$ para $49 \%$, respectivamente.

As diferenças de consumo entre homens e mulheres estão relacionadas diretamente ao abuso $^{7}$ da substância, que é mais frequente em homens. No entanto, estudos apontam o uso exagerado de álcool entre mulheres.

O I Levantamento Domiciliar Sobre o Uso de Drogas Psicotrópicas no Brasil, realizado em 2001, aponta que 60,6\% das mulheres brasileiras fizeram uso de álcool em algum momento da vida. Entre a população jovem, na faixa etária entre 18 e 24 anos, o número foi de $68,2 \%$; o mesmo estudo aponta $5,7 \%$ da população feminina do Brasil com diagnóstico de dependência.

No II Levantamento Domiciliar, realizado em 2005, pesquisadores constataram que o uso de álcool entre mulheres cresceu, em relação ao I Levantamento. O consumo passou para 68,3\%; a faixa etária em destaque foi de 25 a 34 anos de idade; com $73 \%$ de menção ao uso de álcool na vida. No que diz respeito à dependência da substância, também foi constatado o aumento para $6,9 \%$, entre as mulheres entrevistadas.

\footnotetext{
${ }^{6}$ A quantidade que define "beber em binge" foi estabelecida por inúmeros estudos em cinco doses para homens e quatro doses para mulheres, em uma só ocasião.

${ }^{7}$ Segundo o Manual de Diagnóstico e Estatístico de Transtornos Mentais da Associação América (DSMVI), o abuso baseia-se na ocorrência de um ou mais dos seguintes critérios, no período de 12 meses: 1. Uso recorrente que resulta no fracasso de atividades importantes, no trabalho, na escola ou em casa. 2. Uso recorrente em situações que representam perigo físico. 3. Problemas legais resultantes do uso da substância. 4. Uso continuado, apesar dos problemas sociais ou interpessoais persistentes ou recorrentes, causados ou exacerbados pelos efeitos da substância.
}

Serv. Soc. \& Saúde, Campinas, SP v. 12, n. 2 (16), p. 237-258, jul./dez. 2013 ISSN 1676-6806 
A literatura tem apontado que um dos estimuladores, para a relação abusiva que o gênero feminino faz do álcool, está relacionado à ampliação do papel social das mulheres na sociedade moderna. Para Pereira Dantas (2012), “esse crescimento está associado às mudanças de comportamento social e à entrada da mulher no mercado de trabalho, na vida política" (ibid., p. 240).

Pode-se também acrescentar, aos apontamentos da autora, aspectos relacionados às desigualdades sofridas, nos espaços públicos e privados da vida em sociedade, e também às exigências sociais que lhe é imputada, como forma de fortalecer e galgar espaços sociais, até então pensados como "exclusivos" do gênero masculino.

Essas questões, dentre outras, tornaram-se bandeiras de reivindicação que, na maioria das vezes, apresentam às mulheres "contas sociais". Sobre isso, citam-se como exemplos a desigualdade salarial e os crescentes índices de violência, cujas principais vítimas são as mulheres.

Pode-se ainda pensar sobre quais outras contas sociais são imputadas às mulheres e se há relação entre essas contas e o uso abusivo de álcool.

Pereira Dantas (2012) observa, em seu levantamento bibliográfico, que a maior ocorrência do uso abusivo de álcool foi constatada em pesquisas realizadas nas regiões norte e nordeste. Outro dado, apontado pela autora como preocupante, é o percentual de $5,2 \%$ de adolescentes dependentes, entre a faixa etária de 12 a 17 anos; no caso do nordeste, esse número aproxima-se de $9 \%$.

Como resultado, apreende-se que esses adolescentes, não tendo o devido acompanhamento de saúde, estão sujeitos a serem adultos dependentes de álcool, e mais vulneráveis, ao longo da vida, aos danos físicos, psíquicos e sociais decorrentes do consumo exagerado da substância.

De acordo com Pereira Dantas (2012), os estudos locais, realizados nas regiões norte e nordeste, “[...] mostram que há uma predisposição para o uso e abuso do álcool e uma tendência ao alcoolismo feminino" (ibid, p. 241).

A autora destaca, ainda, os fatores que podem contribuir para o "estreitamento" da relação das mulheres com o álcool, como as limitações físicas ou crônicas, insegurança, baixa tolerância ao fracasso e dor, dificuldades e temores para estabelecer relações interpessoais, dentre outras dificuldades. Aspectos que podem ser compreendidos como "gatilhos", ao aproximá-las do uso abusivo de álcool. Serv. Soc. \& Saúde, Campinas, SP v. 12, n. 2 (16), p. 237-258, jul./dez. 2013 ISSN 1676-6806 
Acrescentam-se, a esses fatores, a destituição dos papéis socialmente atribuídos às mulheres. Podem ser citadas como exemplo, mulheres que têm as suas atividades restritas ao espaço privado da vida social como: os cuidados com os companheiros, filhos ou aos demais membros adoecidos do núcleo familiar. A perda desse papel social, causada tanto pelo fim dos relacionamentos, saída dos filhos de casa, ou morte de familiares, pode contribuir para a aproximação da substância, em dado momento da vida adulta, já que, um dos elementos constitutivos da identidade da mulher, está restrito ao espaço privado de reprodução da vida cotidiana.

Isso é apontado por Pereira Dantas (2012): "Muitas mulheres casadas começam a beber na meia-idade, quando o seu papel de mãe e esposa é desafiado pela partida de seus filhos" (ibid., p. 241). Os elementos relacionados ao álcool, no universo feminino, foram e são apontados em diferentes estudos.

O I Levantamento Nacional sobre os Padrões de Consumo de Álcool na População Brasileira cita o estudo realizado em 2002, pelo Banco Mundial, que apresenta as importantes diferenças entre homens e mulheres, no que tange ao consumo de álcool, em especial, “como homens tendem a beber mais e a ter maiores prejuízos em relação ao álcool, enquanto as mulheres sofrem mais com a violência relacionada ao seu consumo" (BRASIL, 2007, p. 9).

O I Levantamento traz ainda, a necessidade de implementar políticas públicas, com o objetivo de diminuir o custo social do uso abusivo de álcool e, principalmente, considerar as diferenças entre os gêneros como elemento fundamental, ao definir essas políticas.

Para compreender os impactos do uso abusivo entre as mulheres, é importante também pensar, na categoria de gênero, como uma das lentes a serem utilizadas na busca pelo entendimento e implementação do atendimento integral a esse público.

\section{GÊNERO: CATEGORIA ANALÍTICA A SER UTILIZADA EM PRÁTICAS DEMOCRÁTICAS DE SAÚDE}

Nas últimas décadas, diferentes setores organizados da sociedade vêm incluindo a condição da mulher na sociedade em suas pautas de discussão. O movimento feminista e o movimento de mulheres integram esses setores que, desde a década de 1970, dão visibilidade às questões relacionadas à vida da mulher.

Serv. Soc. \& Saúde, Campinas, SP v. 12, n. 2 (16), p. 237-258, jul./dez. 2013 ISSN 1676-6806 
A mobilização social dos movimentos que atuam com a problemática, fomentou a discussão e a da categoria de análise que permite compreender criticamente a situação da mulher na sociedade e contribui para a emergência da categoria analítica gênero.

Gênero é uma gramática sexual que estabelece regras sociais para homens e mulheres. Sirqueira (2009) cita Amaral que destaca em seu estudo ${ }^{8}$ a existência das regras sociais em todas as sociedades de que se tem notícia, configurando-se, assim, como fato histórico. A categoria de análise, gênero, apresenta elementos que permitem compreender as relações sociais entre homens e mulheres, ou seja, as relações de gênero.

Essas relações são regidas pela gramática sexual, que estabelece os comportamentos socialmente permitidos e não permitidos para homens e mulheres. Para Saffioti $^{9}$ (2004):

No plano das representações existe, assim, uma verdadeira gramática sexual, indicando as condutas aceitas para homens e os comportamentos admitidos para mulheres [...] O gênero participa, portanto, do processo de construção do sujeito, da mesma forma que a raça/etnia e a classe social (ibid., p. 36-37).

As sociedades estruturam regras comportamentais que são imputadas a homens e mulheres em seus processos de socialização. Os papéis sociais, que são colocados aos indivíduos de ambos os gêneros, podem ser contestados pelos indivíduos, como também internalizadas por eles, sem crítica.

No geral, esses moldes de socialização têm obtido sucesso, pois os indivíduos introjetam as normas impostas, implícitas ou explícitas, nas relações de gênero. "Nesse aspecto, é importante destacar que os mecanismos sociais, sobretudo no capitalismo, são sutis e transformam em naturais construções sociais" (SIRQUEIRA, 2009, p. 6).

Considerando as relações de gênero como um processo social e histórico que têm na sociedade, instrumentos difusos para "maquiar" a realidade social, uma análise crítica que lance mão de uma bagagem teórica sólida, é de suma importância, como forma de compreender e romper com as desigualdades de gênero. De acordo com Sirqueira citando Amaral

\footnotetext{
${ }^{8}$ O Conselho Estadual da Condição Feminina do Estado de São Paulo - Um Estudo Acerca das Bases Históricas da sua Construção, Limites e Contradições.

${ }^{9}$ Diferença ou Indiferença: Gênero, Raça/Etnia, Classe Social, texto contido no Caderno n. 8 - Políticas Públicas e Igualdade de Gênero.

Serv. Soc. \& Saúde, Campinas, SP v. 12, n. 2 (16), p. 237-258, jul./dez. 2013 ISSN 1676-6806
} 
A internalização ocorre, pois a ideologia dominante impõe na maioria das situações o pensamento dominante que é o masculino. As mulheres e os homens reproduzem, muitas vezes sem perceber e incorporam o papel tradicional a eles atribuído socialmente. Desta forma se dá a construção sócio-histórica das figuras relacionadas tanto ao feminino, quanto ao masculino (AMARAL apud SIRQUEIRA, 2009, p.14-15).

Karl Marx, em seu artigo Sobre o Suicídio ${ }^{10}$ (2006), apresenta um dos primeiros escritos sobre a condição da mulher na sociedade capitalista burguesa. Ele selecionou e analisou trabalhos do autor Jacques Peuchet ${ }^{11}$ sobre aspectos da vida privada da sociedade francesa, principalmente o suicídio.

No artigo, Marx apresenta o contraponto entre o resultado de uma das expressões da Questão Social, o suicídio, tendo como recorte a opressão contra as mulheres da sociedade moderna. Analisa quatro casos, dos quais três são de mulheres vítimas do patriarcado. Para Peuchet/Marx, são vítimas da "tirania familiar".

É importante localizar a família no cenário social, como uma das instituições formadoras e também influenciadas pelos mecanismos de dominação da sociedade patriarcal e burguesa. Nesse sentido, desempenha um dos principais papéis, a formação dos indivíduos, de fundamental importância até os dias atuais, já que a família é o primeiro espaço de socialização dos sujeitos.

Nos três casos analisados por Peuchet/Marx, dois são de mulheres "burguesas" e, o terceiro, de origem proletária, filha de um alfaiate. $\mathrm{O}$ elemento comum que une os três casos é a questão de gênero.

O primeiro caso apresenta uma jovem que, ao ser mantida em cárcere por seus pais, utiliza o suicídio como um ato de rompimento da situação vivenciada.

Sob esse aspecto, ainda se presenciam situações como essas, vivenciadas por inúmeras mulheres, em diferentes sociedades que entendem o gênero feminino como propriedade, nesse caso, o "proprietário", na maioria das vezes, é o indivíduo masculino. O segundo caso é de uma mulher que também foi mantida em cárcere, desta vez, por seu marido. Novamente, observa-se o poder do masculino sob o feminino.

Nesse sentido, o fortalecimento das sociedades patriarcais incentiva também o avanço do poder masculino. Pode-se exemplificar a questão por meio do medo, controle

\footnotetext{
${ }^{10}$ Marx publicou o artigo Sobre o Suicídio em 1946, no exílio, em Bruxelas.

${ }^{11}$ Jacques Peuchet (1758-1830) era um ex-arquivista policial. Os altos números de suicídios da época o levaram a traçar uma breve e detalhada análise das relações e dos comportamentos humanos da sociedade daquele momento.
}

Serv. Soc. \& Saúde, Campinas, SP v. 12, n. 2 (16), p. 237-258, jul./dez. 2013 ISSN 1676-6806 
e das diferentes expressões de violência que vitimam as mulheres. $\mathrm{O}$ terceiro e último caso, apresentado pelos autores, é a história de uma jovem que deseja interromper a gravidez, mas o conflito com as regras socialmente impostas pela sociedade da época, a impede de exercer o direito sobre o próprio corpo, o que a incentiva a cometer o suicídio.

A temática do último caso, o direito ao aborto, torna-se, mais tarde, uma das principais bandeiras do Movimento Feminista, na discussão pelos direitos sexuais e reprodutivos das mulheres, pauta essa que ainda enfrenta grande resistência, nos dias atuais, dos setores organizados da sociedade.

Nesse sentido, os casos de suicídio têm aspectos sociais semelhantes, que é a opressão da sociedade patriarcal burguesa sobre a mulher. Nos dias atuais, essa opressão é exemplificada por meio da desigualdade salarial, entre homens e mulheres, que se perpetua. Pesquisas apontam que, mesmo com melhores qualificações, as mulheres permanecem recebendo menores salários. Esse é um dos exemplos, mas é possível acrescentar a essa lista outras desigualdades sociais.

Em consequência dessas questões, os rebatimentos dessas desigualdades manifestam-se na área da saúde, em que os desdobramentos das questões de gênero apresentam-se, às vezes, de forma visível; outras, de maneira "disfarçada".

A categoria teórica de gênero, para ser considerada necessária na abordagem em saúde, precisa também ser compreendida para além do processo de adoecimento.

Nesse aspecto, a concepção de saúde trabalhada nesse estudo perpassa pelo entendimento ampliado do tema. Aprofundando essa visão, Kruger (2010, p. 128) apoia-se em Arouca (1987) para citar:

Saúde não é simplesmente não estar doente, é mais: é um bem-estar social, é o direito ao trabalho, a um salário condigno; é o direito a ter água, à vestimenta, à educação e até, a informação sobre como se pode dominar o mundo e transformá-lo. É ter direito a um meio ambiente que não seja agressivo, mas que, pelo contrário, permita a existência de uma vida digna e decente; a um sistema, político, que respeite a livre opinião, a livre possibilidade de organização e de autodeterminação de um povo. É não estar todo tempo submetido ao medo da violência, tanto daquela violência de um governo contra o seu próprio povo, para que sejam mantidos os interesses que não sejam os do povo (AROUCA, 1987, p. 36). 
Nesse sentido, as determinações sociais do binômio saúde/doença, dizem respeito às condições coletivas de existência que por sua vez, devem ser consideradas na abordagem em saúde e no caso, no atendimento de mulheres que fazem uso abusivo do álcool. Assim, saúde é reconhecida como resultante das condições de vida dos indivíduos; condições essas que estão atreladas às questões econômicas, culturais, políticas e sociais.

O caráter social da doença, segundo Laurell (1982) não é observado pelo caso clínico, mas, sim, pela maneira como o indivíduo adoece e morre nos grupos humanos. A autora exemplifica a questão com a historicidade da tuberculose.

[...] Ainda que provavelmente a história natural da tuberculose, por exemplo, seja diferente, hoje, do que era há cem anos, não é nos estudos dos tuberculosos que vamos apreender melhor o caráter social da doença, porém nos perfis patológicos que os grupos sociais apresentam (ibid., p. 3).

Desta maneira, entende-se que a apreensão do processo histórico das desigualdades sociais no processo saúde/doença dos indivíduos pode auxiliar no atendimento pautado em uma visão integral de saúde.

Quando são discutidas as desigualdades sociais na área da saúde, fala-se de aspectos sociais que de alguma maneira, colocam os indivíduos ou determinados grupos sociais em desvantagem, em relação aos demais. De acordo com Sirqueira (2009, p. 10) que cita Amaral (2006),

A intersecção da categoria raça/cor como outras, tais como gênero e classes sociais, evidenciam fortes contrastes nas vivências de homens e mulheres, brancos e negros, ricos e pobres na sociedade brasileira. Esses contrastes incidem transversalmente nas esferas da vida social, refletindo-se no acesso à educação, saúde, qualidade de vida (saneamento básico, água encanada, esgoto tratado), inserção no mercado de trabalho, acesso à informação, justiça e cidadania (AMARAL apud SIRQUEIRA, p. 10).

As desigualdades, também podem ser entendidas como desdobramentos das expressões da Questão Social que se refletem na saúde, assim como em áreas estratégicas para o desenvolvimento pleno dos indivíduos. 


\section{DESIGUALDADES SOCIAIS EM SAÚDE: DESDOBRAMENTOS DA QUESTÃO SOCIAL}

Os principais registros sobre as desigualdades sociais em saúde datam do século XIX. As condições sociais e políticas oriundas do surgimento do capitalismo na fase da produção industrial propiciaram o desenvolvimento do tema, tanto pelas condições de vida impostas à classe trabalhadora, quanto pelas revoluções burguesas, impulsionadas pelo ideário político da época.

As desigualdades sociais em saúde são observadas em grupos populacionais que têm em comum as dificuldades de acesso aos bens e serviços essenciais, manifestadas em áreas estratégicas para a formação de indivíduos saudáveis como: educação, trabalho, condições de moradia, acesso à riqueza socialmente produzida pela nação, etc.

As diferenças sociais têm como "fio condutor" a dificuldade de acesso à riqueza socialmente produzida que ao mesmo tempo, está vinculada diretamente à Questão Social e as suas diferentes expressões. A gênese da Questão Social está calcada na contradição entre as classes e a apropriação privada do trabalho, assim como seus frutos. Sobre o tema, Iamamoto (2006) destaca:

Questão Social apreendida como um conjunto das expressões das desigualdades da sociedade capitalista madura, que tem uma raiz comum: a produção social é cada vez mais coletiva, o trabalho tornase mais amplamente social, enquanto a apropriação dos seus frutos mantém-se privada, monopolizada por uma parte da sociedade (ibid., p. 27).

Sob essa perspectiva, compreender como a Questão Social intervém na vida dos sujeitos sociais é também decifrar as desigualdades sociais, a partir do olhar sobre as diferenças de classe, com recortes de gênero, raça/etnia, religião, etc. Iamamoto (2006, p. 25) aponta ainda que:

As desigualdades sociais sempre existiram e existirão, o que se pode fazer é minimizar as manifestações extremas da pauperização, por meio de uma melhor distribuição dos produtos do trabalho desde que mantida intocada a distribuição dos meios de produzir e, portanto, as bases sociais em que se erige a sociedade de classes (ibid., p. 25).

Entende-se que os impactos das desigualdades sociais nos indivíduos podem ser minimizados por meio da divisão igualitária das riquezas socialmente produzidas. 
Riquezas essas que são usufruídas pela população por meio dos bens e serviços oferecidos pelas políticas públicas realizadas pelo Estado.

No Brasil, a Constituição Federal (CF) de 1988 introduziu avanços com o objetivo de corrigir injustiças sociais com raízes históricas. O artigo 196 da CF aponta:

A saúde é direito de todos e dever do Estado, garantindo mediante políticas sociais e econômicas que visem à redução do risco de doenças e de outros agravos e ao acesso universal e igualitário às ações e serviços para a sua promoção, proteção e recuperação (BRASIL, CF, art. 196).

A CF garantiu o direito universal à saúde, cabendo ao Estado o papel de responsável por viabilizá-la, por meio de política específica que mais tarde se efetivou com o Sistema Único de Saúde (SUS), materializando as ações e os serviços que passaram a ser considerados de relevância pública, buscando assim, atuar nos determinantes e condicionantes de saúde.

Esses aspectos também estão preconizados na Lei 8.080/1990, que aponta no artigo $3^{\underline{0}}$ :

A saúde tem como fatores determinantes e condicionantes, entre outros, a alimentação, a moradia, o saneamento básico, o meio ambiente, o trabalho, a renda, a educação, o transporte, o lazer e o acesso aos bens e serviços essenciais; os níveis de saúde da população expressam a organização social e política do País.

Discutir condicionantes e determinantes que incidem sobre a saúde leva, ao mesmo tempo, a entender como as condições de moradia, trabalho, renda, educação, entre outros fatores, podem influenciar nas condições de nascer, viver e morrer dos indivíduos. Em relação a esse aspecto, Iamamoto (2006) cita a discussão de Marx e Engels contida no livro Ideologia Alemã: “[...] para viver é preciso comer, beber, ter habitação, vestir-se e algumas coisas mais. O primeiro ato histórico é, portanto, a produção de meios que permitam a satisfação dessas necessidades, a produção da própria vida material” (MARX, ENGELS, apud IAMAMOTO, 2006, p. 26).

No caso do atendimento de saúde das mulheres, é importante considerar, na abordagem técnica, não só aspectos relacionados à doença, mas também elementos que contribuíram e contribuem para o processo de adoecimento e piora na condição de saúde desse público.

Considerar o aspecto gênero como uma das expressões da Questão Social no processo de adoecimento e também na abordagem técnico-profissional é contribuir para 
construir uma abordagem integral da prática em saúde. Questões objetivas e subjetivas de vida podem determinar não só o espaço da mulher na sociedade, mas também sua aproximação de substâncias nocivas à saúde, como é o caso do álcool.

\section{A QUESTÃo DE GÊNERO COMO CATEGoria TRANSVERSAL NA PROMOÇÃO DA INTEGRALIDADE DA SAÚDE}

O Serviço Social no campo da saúde tem seus próprios e tradicionais espaços de atuação. Com a estruturação do SUS, foram ampliadas suas abordagens, com enfoques multidisciplinares e intersetoriais, assim como as ações em áreas estratégicas de gestão, planejamento de políticas públicas e também no desenvolvimento de pesquisas.

Os princípios do SUS, os fundamentos da Reforma Sanitária e o Projeto ÉticoPolítico da profissão, têm semelhanças que perpassam não só pelo momento histórico em que foram pensados, como também pelo modelo societário democrático que almejavam. Sobre isso, Kruger (2010) aponta que:

O movimento de renovação do Serviço Social aconteceu em paralelo ao da saúde coletiva, com o Movimento da Reforma Sanitária, inclusive coincidindo em algumas categorias teóricas o debate: Estado, direitos sociais, prática institucional e políticas públicas. De outro modo, esta renovação tanto no Serviço Social, quanto na Saúde aconteceram em meio ao movimento de redemocratização da sociedade brasileira e de renovação das próprias Ciências Sociais, portanto, não se caracterizando como movimentos isolados (ibid., p. 127).

A autora menciona a convergência entre os três projetos políticos. No caso do Serviço Social, a convergência não foi intencional, devido ao processo de revisão interna que a categoria realizava naquele momento histórico. No que tange às bases teóricas, é importante destacar que mesmo não havendo nexo direto com os outros debates sociais e políticos realizados no campo da saúde, o Serviço Social não estava em descompasso com as questões colocadas pela realidade social e política da época.

Para entender as ações do Serviço Social no campo da saúde, é importante também localizar o cenário político no qual a profissão está inserida. Os anos seguintes foram marcados pela implantação e crescimento do projeto neoliberal no Estado, projeto 
esse que confronta diretamente com o projeto ético-político da profissão, da Reforma Sanitária e do SUS.

O diálogo entre os dois projetos não se deu somente no tempo histórico em que foram pensados, mas também nos referenciais éticos e teóricos pautados para a sua construção. Sob esse aspecto, Os Parâmetros para Atuação de Assistentes Sociais na Política de Saúde (2010) apontam que "há uma relação entre o projeto ético-político e o de reforma sanitária, principalmente, nos seus grandes eixos: principais aportes e referências teóricas, formação profisssional e princípios” (CFESS, 2010, p. 24).

Ao mesmo tempo, a Reforma Sanitária apresentou ao assistente social, novas demandas, como:

- Democratização do acesso às unidades e serviços de saúde;

- Construção de estratégias de aproximação e atuação dos serviços e profissionais de saúde com a realidade social;

- Trabalho interdisciplinar;

- Desenvolvimento e foco nas abordagens em grupo;

- Acesso democrático às informações e fomento da participação popular na política de saúde.

Essas novas exigências acarretaram novas respostas e também novos questionamentos dos profissionais, tanto no interior da categoria quanto nos espaços democráticos em que os assistentes sociais estavam inseridos.

Algumas demandas permanecem com o assistente social até os dias atuais, com destaque para a simplificação da Política de Saúde e a democratização do acesso aos serviços da área. Também é possível acrescentar a essas "novas" demandas, a reflexão sobre a condição da mulher na sociedade, expressa muitas vezes, na sala de atendimento social, através de demandas aparentes.

O compromisso com uma atuação profissional pautada na escuta e na construção do vínculo usuário/equipe auxilia na leitura crítica das manifestações das diferentes expressões da Questão Social, apresentadas pela população usuária da política de saúde. Essas necessidades, em alguns casos, apresentam-se "travestidas" por outras necessidades em saúde ou demandas específicas.

É comum, no cotidiano profissional do assistente social, o usuário buscar o atendimento social com determinada solicitação e ao final, o profissional traçar um Serv. Soc. \& Saúde, Campinas, SP v. 12, n. 2 (16), p. 237-258, jul./dez. 2013 ISSN 1676-6806 
plano de trabalho e intervenção que abrange as diferentes dimensões da vida do indivíduo atendido. Nesse sentido, Cecílio (2004) aponta que:

Poderíamos trabalhar com a imagem de que, quando alguém procura um serviço de saúde, está trazendo uma "cesta de necessidades de saúde", que caberia à equipe ter a sensibilidade e preparo para decodificar e saber atender da melhor forma possível (ibid., p. 4).

Para esse autor, o usuário ao procurar o serviço de saúde, apresenta ao profissional, não só uma necessidade, mas múltiplas, expressas na maioria das vezes, em situações de desemprego, dificuldade no acesso aos recursos e serviços públicos de saúde e de outras políticas.

Com base no autor, é possível refletir sobre o atendimento às mulheres adoecidas por uso excessivo de álcool. No atendimento em um serviço de saúde especializado, é importante que o profissional responsável pelo acompanhamento da situação considere, em sua abordagem, questões como: os impactos do uso da substância nas relações familiares daquela usuária; quais os rebatimentos das limitações impostas pelo uso excessivo do álcool; como essa usuária entende o processo de adoecimento do ponto de vista feminino; etc.

Com isso, o profissional considera as questões de gênero, em sua abordagem técnica, ao mesmo tempo em que coloca para a usuária um espaço de escuta que vai além da questão da doença. Sobre isso, Cecílio (2004) aponta também:

Está tudo ali, na "cestinha de necessidades", precisando ser, de alguma forma, escutando, traduzido, pela equipe. Assim, a integralidade da atenção, no espaço singular de cada serviço de saúde, poderia ser definida como o esforço da equipe de saúde de traduzir e entender, da melhor forma possível, tais necessidades, sempre complexas, mas, principalmente, tendo que ser captadas em sua expressão individual (ibid., p. 4).

Para o autor, as necessidades de saúde estão postas, mas ao mesmo tempo, cabe aos profissionais e à equipe um esforço individual e coletivo, para oferecer um atendimento integral.

O esforço não deve ser somente dos profissionais e da equipe dos serviços de saúde, mas também do Estado, por meio da promoção de políticas públicas que visem à melhoria das condições de vida da população. Negligenciar a responsabilidade e o papel do Estado como principal promotor de ações que visem à melhoria da condição de vida 
dos indivíduos é ao mesmo tempo, responsabilizar os profissionais da saúde, e somente eles, por questões que ultrapassam suas capacidades.

\section{REFLEXÕES ACERCA DO TRABALHO COM MULHERES QUE ADOECERAM POR DEPENDÊNCIA DE ÁLCOOL}

As experiências do assistente social no interior das equipes multiprofissionais passaram a apresentar novas possibilidades de atuação profissional. Questões historicamente negligenciadas por abordagens biomédicas e curativas propiciaram para o assistente social, novas possibilidades profissionais.

Dentre essas questões, pode-se apontar a dependência de álcool e a relação das mulheres com a temática de gênero. No atendimento a mulheres adoecidas pela dependência de álcool, observou-se que algumas questões eram comuns, em alguns casos:

- São vítimas de violência física e psicológica;

- Fuga de sua cidade ou região de origem, como alternativa para romper o ciclo de violência;

- Situação de rua;

- Tentativa de reconstrução da vida e na maioria dos casos, uma das alternativas encontradas estava em um novo relacionamento;

- Modelo idealizado e naturalizado de família e a busca incessante pela constituição de um núcleo familiar, com base no modelo socialmente imposto;

- Fragilidade na construção dos vínculos familiares;

- Culpabilização pela fragilidade dos vínculos familiares;

- Na maioria dos casos, a verbalização do uso do álcool como forma de suporte para a situação vivida.

A respeito das violências física e psicológica, as mulheres atendidas se identificam como vítimas da violência física, mas nem sempre da psicológica. $\mathrm{Na}$ maioria dos casos atendidos, os algozes são os companheiros.

Várias mulheres encontraram, como forma de romper o ciclo de violência, a fuga de sua cidade ou estado de origem. Elemento marcante nas tentativas de construção 
de novas histórias de vida. É o modelo idealizado de família e a busca pela constituição de um núcleo familiar com base nos moldes socialmente construídos.

A idealização do modelo "perfeito" de família, muitas vezes, não contribui para a visualização de ganhos individuais que essas mulheres adoecidas pela dependência do álcool obtiveram em sua trajetória de vida. As dificuldades em constatar as conquistas alcançadas, muitas vezes, propiciaram o estreitamento com o uso da substância e em alguns casos, a intensificação do uso do álcool.

Percebe-se que, assim como no universo masculino, o álcool no universo feminino, também pode contribuir para o esgarçamento dos vínculos afetivos. No entanto, quando se trata da mulher, as cobranças pelo desempenho pleno do papel de mãe, esposa e cuidadora da família, adquirem formas inquisitórias, já que a dependência do álcool prejudica o desempenho não só desses papéis, mas também a inserção da mulher em outros espaços da vida social.

O processo de fragilização e culpabilização pelo não desempenho dos papéis socialmente atribuídos, também auxiliam a aproximação dessas mulheres com o álcool, uma vez que, nesses casos, o uso da substância pode constituir uma "rota de fuga" para as situações vivenciadas.

Todos esses elementos só podem ser compreendidos em sua totalidade, a partir de uma análise calcada no processo histórico das relações sociais, tomando a questão de gênero como um recorte dessas desigualdades. Nesse aspecto, o trabalho com mulheres que adoeceram pela dependência do álcool deve transpor as ações restritas ao tratamento da doença.

Entender como as múltiplas expressões da Questão Social apresentam-se na história de vida e no cotidiano das mulheres adoecidas pela dependência do álcool, é também construir alternativas de intervenção profissional, dadas na realidade dessa população.

As ações técnicas voltadas ao atendimento integral são de suma importância, entretanto, não podem ser de inteira responsabilidade das equipes de saúde, mas sim do Estado.

Nesse sentido, diferentes estudos têm apontado que, mesmo com o crescimento do número de mulheres dependentes do álcool, as políticas públicas na área ainda são 
incipientes, aspecto que causa preocupação, já que demonstra a pouca visibilidade social do tema.

\section{CONSIDERAÇÕES FINAIS}

Indivíduos do gênero feminino estão cada vez mais, aproximando-se do uso das drogas lícitas e ilícitas. Como observado no desenvolvimento deste artigo, as desigualdades sociais interferem diretamente no modo como os indivíduos adoecem, ao acentuarem os impactos na vida das mulheres dependentes do uso de álcool.

Ao pensar nesses impactos, não se pode perder de vista em qual cenário - social, econômico e político - a mulher adoecida pelo uso de álcool está inserida. O consumo do álcool em nossa sociedade é mais "bem recebido" no universo masculino do que no feminino; no último caso, o uso é visto com reservas.

As mulheres continuam como as principais vítimas e seus algozes ainda são, na maioria, os companheiros. Nesse aspecto, o uso em excesso de substâncias, como o álcool, pode constituir alternativa de fuga utilizada pelas mulheres para suportar as situações limites $^{12}$ às quais são submetidas.

Essas situações limites podem ser minimizadas com ações programáticas que só podem ser atingidas com intervenções do Estado, por meio de políticas públicas intersetoriais.

No que diz respeito à atuação profissional do assistente social relacionada a essas questões e principalmente, sobre o atendimento às mulheres que fizeram ou fazem uso excessivo de álcool, o contato direto com as usuárias pode ocorrer nos serviços de saúde e nos seus diferentes níveis de atendimento (Básica, Média e Alta Complexidade). Essas ações, em sua maioria são realizadas no atendimento direto, nas dimensões terapêutica, interdisciplinar e socioeducativa.

Essas intervenções não acontecem isoladamente, elas são interligadas, o que exige que o profissional em sua atuação utilize a investigação crítica como ferramenta para o entendimento da realidade, das relações sociais e do processo de adoecimento das mulheres atendidas ${ }^{13}$.

\footnotetext{
${ }^{12} \mathrm{O}$ termo situações limites utilizado no texto faz referência à pobreza, dificuldade de acesso à educação, ao trabalho, à moradia, etc.

${ }^{13}$ Trata-se da investigação utilizada como ferramenta fundamental para a produção de diferentes saberes e não somente para a atuação do assistente social.

Serv. Soc. \& Saúde, Campinas, SP v. 12, n. 2 (16), p. 237-258, jul./dez. 2013 ISSN 1676-6806
} 
Outro aspecto a ser considerado refere-se ao rompimento com ações de caráter emergencial e burocrático, a fim de contribuir na construção de ações que auxiliem as usuárias a refletirem criticamente sobre as suas condições de vida. Essas condições de vida ao serem analisadas a partir da categoria analítica de gênero, podem tomar contornos diferentes. Esses contornos têm como marca a naturalização das desigualdades e a consequente permanência da subalternidade do gênero feminino.

Nesse sentido, o assistente social pode ter como um dos focos de sua intervenção profissional, os espaços de reflexão sobre a questão de gênero com as usuárias dos serviços e também com a equipe de saúde. Os Parâmetros para Atuação de Assistentes Sociais na Política de Saúde (2010) apontam:

O assistente social, ao participar de trabalho em equipe na saúde, dispõe de ângulos particulares de observação na interpretação das condições de saúde do usuário e uma competência também distinta para o encaminhamento das ações, que o diferencia do médico, do enfermeiro, do nutricionista e dos demais trabalhadores que atuam na saúde (ibid., p. 44).

Esse trabalho pode auxiliar as mulheres em acompanhamento a iniciarem uma reflexão crítica e, por sua vez a desconstrução de questões que envolvam as relações de gênero e principalmente, a localizarem em suas histórias de vida, aspectos relacionados a essas desigualdades que propiciaram a aproximação com o uso abusivo do álcool.

Nesse aspecto, é necessário o estímulo a ações que busquem a ampliação de modelos inovadores de atenção ao processo de saúde e doença. Esses modelos inovadores, atrelados à perspectiva crítica do desvelamento das relações sociais de gênero das usuárias dos serviços de saúde, podem constituir-se como uma importante ferramenta de enfrentamento da Questão Social no interior dos serviços de saúde.

Modelos de atenção em saúde, calcados nesses princípios, estão próximos não só dos princípios da Reforma Sanitária e do SUS, mas também do compromisso ético do assistente social. Dentre esses compromissos, podem ser destacadas ferramentas importantes para os profissionais inseridos na Política de Saúde, contidas nos Princípios Fundamentais do Código de Ética Profissional do Assistente Social ${ }^{14}$ :

\footnotetext{
${ }^{14}$ Código de Ética aprovado em 13 de março de 1993.

Serv. Soc. \& Saúde, Campinas, SP v. 12, n. 2 (16), p. 237-258, jul./dez. 2013 ISSN 1676-6806
} 
- Reconhecimento da liberdade como valor ético central e das demandas políticas a ela inerentes - autonomia, emancipação e plena expansão dos indivíduos sociais;

- Ampliação e consolidação da cidadania, considerada tarefa primordial de toda a sociedade, com vistas à garantia dos direitos civis, sociais e políticos das classes trabalhadoras;

- Defesa do aprofundamento da democracia, enquanto socialização da participação política e da riqueza socialmente produzida;

- Posicionamento em favor da equidade e justiça social, que assegure a universalidade de acesso aos bens e serviços relativos aos programas sociais, bem como sua gestão democrática;

- Empenho na eliminação de todas as formas de preconceito, incentivando o respeito à diversidade, à participação de grupos socialmente discriminados e à discussão das diferenças;

- Opção por um projeto profissional vinculado ao processo de construção de uma nova ordem societária, sem dominação/exploração de classe, etnia e gênero;

- Compromisso com a qualidade dos serviços prestados à população e com o aprimoramento intelectual, na perspectiva da competência profissional.

Nesse sentido, respaldar-se nos princípios do Código de Ética da profissão, auxilia no direcionamento de práticas integrais em saúde que podem contribuir para romper com práticas rotineiras, burocráticas e acríticas, e assim direcionar as ações para uma intervenção profisssional a partir da investigação da realidade social à qual as usuárias dos serviços de saúde estão ou estiveram submetidas.

Ações profissionais que visem à abordagem integral não devem ser compreendidas como restritas à profissionais ou a serviços de saúde, mas sim, a práticas profissionais interdisciplinares e intersetoriais, que têm o Estado como um dos principais promotores, com a oferta de políticas públicas que minimizem as injustiças sociais. 


\section{REFERÊNCIAS}

BRASIL. I Levantamento Nacional sobre os Padrões de Consumo de Álcool na População Brasileira. 2007. Disponível em: <http://www.obid.senad.gov.br>.

Acesso em: 19 mar. 2013.

BRASIL. II Levantamento Nacional de Álcool e Drogas (LENAD-2012).

Disponível em: <http://www.impad.org.br/LENAD_PressRelease>. Acesso em: 10 out. 2013. BRAVO, MIS... [et al.]. (Orgs.). Saúde e Serviço Social. 4. ed. São Paulo: Cortez; Rio de Janeiro: UERJ, 2009.

CARVAlHO, G. Fundo Municipal de Saúde. São Paulo: Instituto Pólis/ PUC-SP, 2003. 104 p.

CENTRO DE INFORMAÇÕES SOBRE SAÚDE E ÁLCOOL. Álcool e mulheres. Disponível em: <http://www.cisa.org.br>. Acesso em: 25 fev. 2013.

Diferenças entre gêneros em relação ao padrão de consumo de álcool e problemas relacionados em uma amostra representativa de São Paulo. Disponível em: <http://www.cisa.org.br>. Acesso em: 25 fev. 2013.

CECILIO, L. C. O. As necessidades de saúde como conceito estruturante na luta pela integralidade e equidade na atenção à saúde. Lappis - Laboratório de Pesquisa sobre Práticas de Integralidade em Saúde. Rio de Janeiro: ENSP, 2004.

Disponível em: <http://www.lappis.org.br>. Acesso em: 5 mar. 2013.

CONSELHO FEDERAL DE SERVIÇO SOCIAL. Parâmetros para atuação de assistentes sociais na política de saúde. Série Trabalho e Projeto Profissional nas Políticas Sociais, n. 2, Brasília: CFESS, 2010.

ELBREDER, M. F. [et al.]. Perfil de mulheres usuárias de álcool em ambulatório especializado em dependência química. Jornal Brasileiro de Psiquiatria [on-line]. 2008, v. 57, n.1, p. 9-15. Disponível em: <http://www.scielo.br>. Acesso em: 10 mar. 2013.

GODINHO, T.; SILVEIRA M. L. de (Orgs.). Políticas públicas de gênero. São Paulo: Coordenadoria Especial da Mulher, 2004. 188p. Cadernos da Coordenadoria Especial. A Mulher, 8 .

IAMAMOTO, M. Serviço social na contemporaneidade: trabalho e formação profissional. 10. ed. São Paulo: Cortez, 2006. 
KRUGER, T. R. Serviço Social e saúde: espaços de atuação a partir do SUS. Revista Serviço Social \& Saúde, Campinas, v. IX, n.10, p.123-145, dez. 2010.

MARX, K. Sobre o suicídio. Tradução de Rubens Enderle e Francisco Fontanella. São Paulo: Boitempo, 2006.

MARX, K.; ENGELS, F. A Ideologia alemã. São Paulo: Grijalbo, 1977, p. 39.

MATTOS, R. A. de. A integralidade na prática (ou sobre a prática da integralidade). Caderno Saúde Pública, Rio de Janeiro, v. 20(5), p.1411-1416, set./out. 2004. NOGUEIRA, V. M. R.; MIOTO, R. C. T. Desafios atuais do sistema único de saúde - SUS e as exigências para os assistentes sociais. In: MOTA, A. E...[et al.]. (Orgs.). Serviço Social \& Saúde: formação e trabalho profissional. 4. ed. São Paulo: Cortez; Brasília (DF): Opas, OMS, Ministério da Saúde, 2009.

PEREIRA DANTAS, I. S. S. Produção científica no Brasil sobre álcool e mulher: uma revisão bibliográfica. Disponível em:

$<$ http://www.uel.br/revista/uel/index.php/ssrevista>. Acesso em: 24 mar. 2013.

SEVERINO, AJ. Metodologia do trabalho científico. 23. ed. rev. e atual. São Paulo: Cortez, 2007.

SILVA, J. P. V. da; GULJOR, A. P. Gestão em redes e construção da integralidade da atenção e do cuidado em saúde: notas para um debate. Disponível em: <http://www.acervo.espsjv.fiocruz.br/beb/textocompleto>. Acesso em: 10 mar. 2013. SIRQUEIRA, D. S. Mulheres que contraíram HIV em relacionamentos estáveis e relações de gênero. (Monografia de Aprimoramento Profissional) - Secretaria de Estado da Saúde de São Paulo, São Paulo, 2009. 